\title{
Comparison of Presentation, Course, and Outcome of Congenital and Acquired Cytomegalovirus Infection in Twins
}

\author{
Veronica Mugarab Samedi, MD ${ }^{1}$ Christopher Skappak, BSc ${ }^{2}$ Lindsay Jantzie, MD, BSc ${ }^{2}$ \\ Cynthia Trevenen, MD, FRCPC ${ }^{3}$ Majeeda Kamaluddeen, MD, FAAP ${ }^{1}$ Pauline Ekwalanga, MD, FRCSC \\ Essa Hamdan Al Awad, MD ${ }^{1}$
}

${ }^{1}$ Section of Neonatology, University of Calgary, Alberta, Calgary, Canada

2 Department of Family Medicine, University of Calgary, Alberta, Calgary, Canada

${ }^{3}$ Department of Pathology and Laboratory Medicine, University of Calgary, Alberta, Calgary, Canada

${ }^{4}$ Department of Obstetrics and Gynecology, University of Calgary, Alberta, Calgary, Canada

Am J Perinatol Rep 2016;6:e1-e5.

Address for correspondence Veronica Mugarab Samedi, MD, Section of Neonatology, University of Calgary, 3500-26 Avenue, Alberta T1Y 6J4, Calgary, Canada (e-mail: Veronica.Samedi@albertahealthservices.ca).

\begin{abstract}
Keywords

- congenital CMV

- acquired CMV

- twins

- thrombocytopenia

- cytogam

- intracranial cysts

- cholestasis

- omega-van

Background Cytomegalovirus (CMV) is one of the most common causes of serious viral intrauterine infections. It is universally distributed among the human population with an average incidence of 0.15 to $2 \%$. Indeed, at least half of the women in the reproductive age have evidence of prior CMV infection.

Epidemiology and Pathogenicity However, it is not a usual practice to screen asymptomatic pregnant woman or neonates for CMV. Even if a mother developed a primary CMV infection during pregnancy, up to $90 \%$ of the newborns with congenital CMV will be asymptomatic at the time of birth. Only 5 to $7 \%$ of the infected babies will be acutely symptomatic, and the typical clinical presentation includes intrauterine growth restriction, microcephaly, various cutaneous manifestations (including petechiae and purpura), hematological abnormalities (particularly resistant thrombocytopenia), hepatosplenomegaly, chorioretinitis, hepatitis, etc. In contrast, acquired CMV infection is extremely unlikely to cause any serious sequelae for the infant.

Cases We present a case of congenital and acquired CMV infection in twins with a focus of dissimilarity in presentation, clinical course, and outcome.
\end{abstract}

The mother of our patients was an asymptomatic 22-year-old gravida 5 , para 2 woman with two previous term vaginal deliveries and two miscarriages at 12 and 13 weeks. She had a spontaneous dichorionic pregnancy with inconsistent prenatal care, marijuana use in the first trimester, and smoking throughout the entire pregnancy. Her prenatal screening showed normal serology, and she denied any history of viral infection during pregnancy. Her first prenatal ultrasound was done at 26 weeks of postmenstrual age and revealed twin A (male) to be small for gestational age with an estimated fetal weight in the 5 th percentile and head circumference below the 3rd percentile. Twin B (female) was appropriate for gestational age. Repeated ultrasound at 30 weeks of gestational age showed that twin A continue to have intrauterine received

February 10, 2015

accepted after revision

June 29, 2015

published online

October 20, 2015
DOI http://dx.doi.org/

$10.1055 / \mathrm{s}-0035-1563387$. ISSN 2157-6998.
Copyright $\odot 2016$ by Thieme Medical Publishers, Inc., 333 Seventh Avenue, New York, NY 10001, USA. Tel: +1(212) 584-4662.
License terms

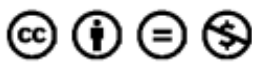


growth restriction with all growth parameters below the 3rd percentile. Twin A' Doppler demonstrated centralization of blood flow, reduced resistance in the middle cerebral artery, and increased peak systolic velocity. The umbilical arterial Doppler waveforms demonstrated intermittent high resistance flow with resistive indices measuring between 0.7 and up to 1.0. Biophysical profile score was $6 / 8$ for absent respiration. There were no findings suggestive for possible CMV infection as intrahepatic or intracranial calcifications. Ultrasonography and Doppler were normal for twin B. The amniotic fluids were normal with a $2 \times 2 \mathrm{~cm}$ pocket for each twin.

In view of persistent severe intrauterine growth restriction, fetal heart rate abnormalities, and breech presentation of twin A, the twins were delivered via cesarean section at 32 weeks gestation. There was no history of maternal fever, the mother was not in labor, and membranes were intact before delivery. Both infants were admitted to the neonatal intensive care unit (NICU) in view of prematurity.

\section{Case 1}

Twin A weighed $840 \mathrm{~g}$ (1st percentile) with head circumference and length at the 3 rd percentile. Apgar scores were 6 and 9 at 1 and 5 minutes, respectively. Immediately upon delivery twin A was found to have scattered petechiae and purpura over the majority of the body and hepatosplenomegaly. There was no obvious dysmorphism. Initial laboratory testing revealed a profound thrombocytopenia (platelets of $5 \times 10^{9} / \mathrm{L}$ ), anemia (hematocrit of 0.31 ), and neutropenia $\left(0.8 \times 10^{9} / \mathrm{L}\right.$ ). Liver enzymes at the age of 24 hours showed elevated gamma-glutamyltransferase of $557 \mathrm{U} / \mathrm{L}$ (normal range, 11$63 \mathrm{U} / \mathrm{L})($ - Table 1$)$.

Toxoplasma, rubella, CMV, herpes simplex, and HIV (TORCH) screening were requested on cord blood and placenta was sent for pathology. Congenital CMV (cCMV) infection was confirmed by placental pathology at 72 hours. Placenta of twin A placenta demonstrated diffuse villitis, CMV inclusions, and strong immunostaining for CMV (-Figs. 1 and 2).

TORCH screen performed on the cord blood was positive for CMV IgM; and polymerase chain reaction (PCR) for CMV genome showed a level of $37,850,000$ copies $/ \mathrm{mL}$.

Twin A had a compound manifestation of cCMV that included multiorgan involvement and required complex management. Initially, he presented with severe thrombocytopenia requiring frequent platelets transfusion (received

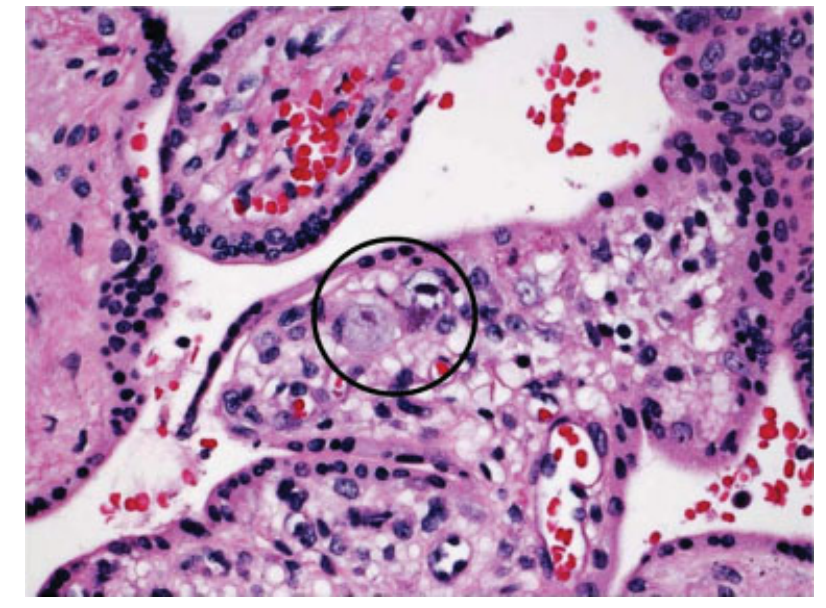

Fig. 1 Hematoxylin and eosin stain of lymphocytic infiltration of the villus and a cytomegalovirus inclusion (black circle) at $\times 200$ magnification.

total 39 units in first 2 months of life) and repeated transfusions of fresh frozen plasma (-Fig. 3).

In view of persistent thrombocytopenia repeated doses of specific CMV hyperimmune immunoglobulin (CytoGam, CSL Behring Canada, Ottawa, Ontario, Canada) were used as potential antiviral therapy for cytomegalovirus neutralization. ${ }^{4}$ Two courses of ganciclovir were used as a basic antiviral therapy. Severe neutropenia (as low as $0.1 \times 10^{9} / \mathrm{L}$ ) and persistent anemia (requiring repeated blood transfusions in the first 2 weeks of life) were explained by probable bone marrow suppression by CMV. Even though initially he had no neurological symptoms, cranial ultrasound on day 5 of life showed heterogeneous, echogenic bilateral masses within the ventricular system indicative of bilateral germinal matrix hemorrhage; magnetic resonance imaging (MRI) at the age of 2 months revealed hyperintensity on fluid attenuated inversion recovery sequences were suggestive of white matter rarefaction and cystic degeneration. 5,6

Liver involvement presented initially as nonspecific hepatitis associated with cholestasis that worsened over the first month of life with the highest level of direct bilirubin 181 $\mu \mathrm{mol} / \mathrm{L}$. He was successfully managed with ursodiol, Omegaven (Fresenius Kabi AG, Bad Homburg, Germany), phenobarbital, and vitamins A, D, E, and K. Hepatobiliary iminodiacetic acid scan revealed mild-to-moderate excess of blood pool activity that indirectly confirmed hepatic dysfunction secondary to CMV hepatitis. ${ }^{4}$

Table 1 Liver function tests for twin A at the first 2 months of life

\begin{tabular}{|l|l|l|l|l|l|l|l|l|}
\hline General chemistry & $\begin{array}{l}\text { Day of } \\
\text { life } \mathbf{1}\end{array}$ & $\begin{array}{l}\text { Day of } \\
\text { life } \mathbf{5}\end{array}$ & $\begin{array}{l}\text { Day of } \\
\text { life 13 }\end{array}$ & $\begin{array}{l}\text { Day of } \\
\text { life 18 }\end{array}$ & $\begin{array}{l}\text { Day of } \\
\text { life 31 }\end{array}$ & $\begin{array}{l}\text { Day of } \\
\text { life } \mathbf{4 2}\end{array}$ & $\begin{array}{l}\text { Day of } \\
\text { life 55 }\end{array}$ & $\begin{array}{l}\text { Day of } \\
\text { life 71 }\end{array}$ \\
\hline Bilirubin total & 148 & 102 & 121 & & 211 & 144 & 72 & 56 \\
\hline Bilirubin Direct & 21 & 62 & 87 & 95 & 181 & 112 & 66 & 41 \\
\hline ALT & 36 & 14 & & & 28 & & & \\
\hline GGT & 575 & 349 & 75 & & 288 & 199 & 142 & 72 \\
\hline
\end{tabular}

Abbreviations: ALT, alanine aminotransferase; GGT, glutamyltransferase. 


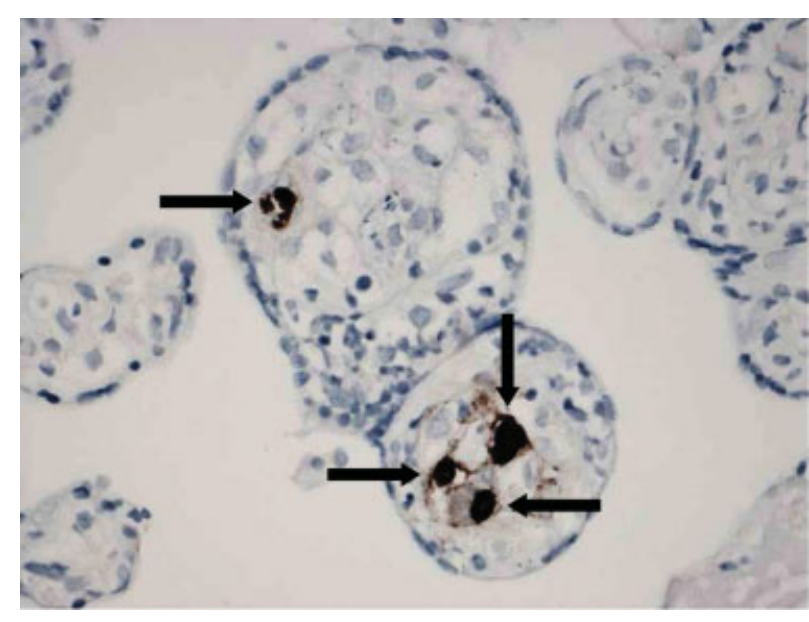

Fig. 2 A cytomegalovirus inclusion (black arrow) at $\times 400$ magnification.

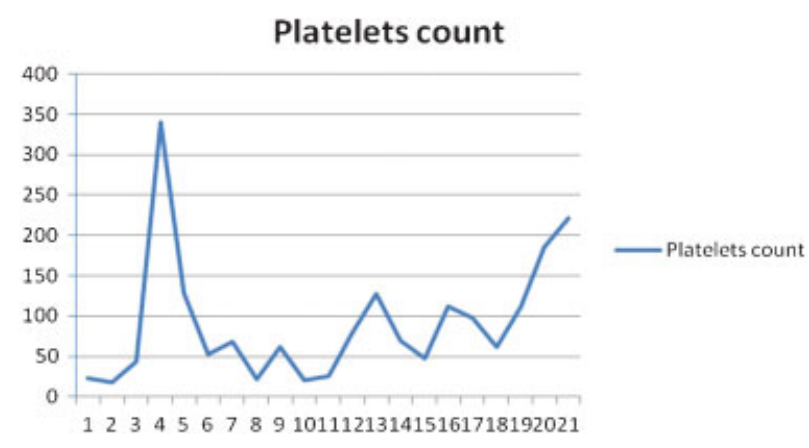

Fig. 3 Platelets trend during first months of life.

He was discharged from NICU at the age of 4.5 months, corrected gestation age 46 weeks, and was followed by a multidisciplinary team for complications of cCMV. At the age of 5 months repeated MRI was done to assess progressive irritability and tremulousness. The findings were suggestive of possible vanishing white matter disease. He was transferred to palliative care; however, his neuromotor development gradually progressed, and by the age of 7 months he showed an ability to learn some new skills. Repeated MRI did not confirm the initial diagnosis of vanishing white matter disease, and additional cystic change in both temporal poles and parietal region were suggestive of late sequelae of CCMV infection. Currently, he is 4 years old, with spastic diplegia and bilateral profound hearing loss, attending Integrated Services for Children with Motor Disabilities School.

\section{Case 2}

Twin B was admitted to the NICU for prematurity with a weight of $1,310 \mathrm{~g}$ (16th percentile), and a head circumference and length at the 20th and the 35th percentile, respectively. Her Apgar scores were 4 and 9 at 1 and 5 minutes, respectively. In contrast to twin A she had no cutaneous lesions and her general examination was unremarkable. Her initial laboratory testing revealed moderate thrombocytopenia (platelets of $39 \times 10^{9} / \mathrm{L}$ ) with mild anemia (hematocrit of 0.34 ) and normal neutrophil level $\left(1.5 \times 10^{9} / \mathrm{L}\right)$. Her liver enzymes were normal (-Table 2).

In view of suspected CMV infection in twin A, TORCH screening on cord blood and placenta pathology were requested. TORCH screen was reported as negative and placental morphology was unremarkable. Clinically, she did not show any symptoms of CCMV.

Her course in the NICU was complicated by late-onset bacterial sepsis (she had coagulase-negative staphylococcus) managed with antibiotics, and necrotizing enterocolitis on the third week of life that required two fresh frozen plasma transfusions. Feeding was restarted with expressed breast milk from her biological mother (breast milk was frozen and rewarmed to minimize risk for CMV transmission). She was clinically recovering until the 5 weeks when she presented with mild-to-moderate thrombocytopenia. Urine CMV culture was requested and came positive, blood PCR for CMV shown 11,900 copies/mL. Her cranial and abdominal ultrasounds were normal, as well as liver and renal function tests. She remained clinically asymptomatic, her platelets stabilized spontaneously and she was discharged from the hospital at the age of 2 months under the care of foster parents.

She was followed up at the pediatric clinic with her brother, and at the age of 4 years, she is a healthy girl who attends regular kindergarten. She has no visual or auditory deficits, and no signs of developmental or motor delay.

\section{Discussion}

CMV belongs to the DNA family of viruses; the only known host for this virus is humans. ${ }^{1}$ Initial infection in healthy individuals can be clinically indistinct, and virus turns into a latent state that can be reactivated due to several causes (superimposed vital infection, poor nutrition, drug use, etc.). In Canada the reported prevalence rate is 0.4 to $1.7 \%{ }^{7-9}$ Although the fetus can be affected by CMV during all trimesters of pregnancy the risk of transplacental infection in first

Table 2 Liver function test for twin B in the first week of life

\begin{tabular}{|l|l|l|l|l|}
\hline General chemistry & Day of life 2 & Day of life 3 & Day of life 4 & Day of life 10 \\
\hline Bilirubin total & 99 & 135 & 155 & 115 \\
\hline Bilirubin direct & & & 5 & 5 \\
\hline ALT & & & 17 & \\
\hline GGT & & & 46 & \\
\hline
\end{tabular}

Abbreviations: ALT, alanine aminotransferase; GGT, glutamyltransferase. 
trimester reaches up to $40 \% .^{10-12}$ of these babies 10 to $15 \%$ are acutely symptomatic at birth, and among these infants up to $80 \%$ will have serious sequelae. ${ }^{2,3}$

Clinical presentation of cCMV can involve all systems that are commonly explained by the spread of CMV virus during fetal viremia and subsequent $\mathrm{T}$-cell response to CMV antigens expressed on the interstitial cells of different organs (liver, brain, lungs, etc.). ${ }^{13,14}$ In contrast, acquired CMV infection (through contamination during delivery or via breast feeding after delivery) rarely causes harmful sequelae. ${ }^{15,16}$

In available literature we found five case reports of dizygotic twins where one of the fetuses got infected with cCMV. ${ }^{10,15,17,18}$ At the present time there is a discrepancy in explaining maternal factors in the outcome of cCMV. Commonly accepted mechanisms of transmission of CMV involve following steps: initially maternal viremia causes placental infection that subsequently initiates fetal viremia. Some authors explain CMV transmission as the result of ineffective suppression of virus replication due to maternal defective immunologic responses. ${ }^{19,20}$ Others prioritize the role of the placenta as a major protective mechanism against the virus. It is confirmed that the placenta is able to produce interferons that acts as a factor limiting viral replication. Another protective action is placental production of HLA-G that plays key role in protecting fetal cells from CMV. ${ }^{13}$ The placental histopathology is one of the best methods to confirm cCMV infection because the placenta is the main entrance for the virus and at the same time the major reservoir where the virus replicates before affecting the fetus.

In describing the above cases only one of the twins had confirmed cCMV infection despite the fact that both the fetuses were exposed to the same viral load at the same period of gestation. cCMV infection in one twin was confirmed by positive histopathological findings in the placenta, while his noninfected sibling showed normal placental pathology. This finding can be explained by the fact that the placenta of the unaffected twin acted as a nonspecific barrier to viral infection. Thus, maternal factors play important, but not absolute roles in predicting the course and outcome of CMV infection. Some authors describe gender as independent risk for complications in cCMV infection. $^{21,22}$ As per their observations, the risk of central nervous system complications and abnormal brain development in infected fetuses was twice as high in females. In our case, the female twin was not affected by CMV in utero; therefore, we cannot make any comments about gender risks for future neurological impairment.

In contrast to congenital cytomegalovirus infection, a postnatally acquired cytomegalovirus infection is not considered as a serious health concern. There are three main mechanisms for developing aCMV: contamination with blood and body fluids during vaginal birth, transmission of the virus during blood product administration, and most commonly via breastfeeding. ${ }^{16,18}$ The outcome for aCMV infection is usually good; it is commonly accepted that in term newborns, cytomegalovirus transmitted via breast milk causes no consequences. At the same time, aCMV may cause severe symptomatic disease in preterm newborns. In certain situations (small for gestational age infants, infants with congenital anomalies, etc.), there is a higher that usual risk of developing cytomegalovirus "sepsis syndrome" which includes apnea, bradycardia, distended bowel, and pallor, and accompanies by laboratory abnormalities such as leukopenia, thrombocytopenia, and elevated C-reactive protein. In the cases described, we are not sure about the route of transmission of CMV. The second twin received blood products as well as breast milk from the CMV-positive mother. Despite the fact that breast milk was frozen and rewarmed to decrease the risks for CMV transmission, we cannot completely exclude this route of transmission. However, her clinical course and outcome for this infant support the idea that freezing breast milk at $-20^{\circ} \mathrm{C}$ may, respectively, reduce the viral load.

The cases described here have shown that twins can react differently to maternal CMV infection; so, clinical course and outcomes cannot be predicted by testing mother by amniocentesis. The definite diagnosis can be done prenatally by amniocentesis or postnatally by performing studies on the placenta and/or newborn infant.

\section{References}

1 Johnson J, Anderson B. Screening, prevention, and treatment of congenital cytomegalovirus. Obstet Gynecol Clin North Am 2014; 41(4):593-599

2 Lanari M, Lazzarotto T, Venturi V, et al. Neonatal cytomegalovirus blood load and risk of sequelae in symptomatic and asymptomatic congenitally infected newborns. Pediatrics 2006;117(1):e76-e83

3 Malm G, Engman ML. Congenital cytomegalovirus infections. Semin Fetal Neonatal Med 2007;12(3):154-159

4 Hart MH, Kaufman SS, Vanderhoof JA, et al. Neonatal hepatitis and extrahepatic biliary atresia associated with cytomegalovirus infection in twins. Am J Dis Child 1991;145(3):302-305

5 Llorente AM, Castillo CL. Congenital cytomegalovirus infection in fraternal twins: a longitudinal case study examining neurocognitive and neurobehavioral correlates. Appl Neuropsychol Child 2012;1(1):63-73

6 Suksumek N, Scott JN, Chadha R, Yusuf K. Intraventricular hemorrhage and multiple intracranial cysts associated with congenital cytomegalovirus infection. J Clin Microbiol 2013;51(7):2466-2468

7 Buonsenso D, Serranti D, Gargiullo L, Ceccarelli M, Ranno O, Valentini P. Congenital cytomegalovirus infection: current strategies and future perspectives. Eur Rev Med Pharmacol Sci 2012; 16(7):919-935

8 Yinon Y, Farine D, Yudin MH. Cytomegalovirus infection in pregnancy. SOGC clinical practice guideline. No. 240, April 2010. Available at: http://sogc.org/wp-content/uploads/2013/01/ gui240CPG1004E.pdf. Accessed April 20, 2015

9 Boppana SB, Ross SA, Fowler KB. Congenital cytomegalovirus infection: clinical outcome. Clin Infect Dis 2013;57(Suppl 4):S178-S181

10 Lazzarotto T, Guerra B, Spezzacatena P, et al. Prenatal diagnosis of congenital cytomegalovirus infection. J Clin Microbiol 1998; 36(12):3540-3544

11 Lazzarotto T, Gabrielli L, Foschini MP, et al. Congenital cytomegalovirus infection in twin pregnancies: viral load in the amniotic fluid and pregnancy outcome. Pediatrics 2003;112(2):e153-e157

12 Lazzarotto T, Guerra B, Lanari M, Gabrielli L, Landini MP. New advances in the diagnosis of congenital cytomegalovirus infection. J Clin Virol 2008;41(3):192-197

13 Chen SF, Holmes TH, Slifer T, et al. Longitudinal kinetics of cytomegalovirus-specific T-cell immunity and viral replication 
in infants with congenital cytomegalovirus infection. J Ped Infect Dis Soc 2014 (e-pub ahead of print). doi: 10.1093/jpids/piu089

14 Lidehäll AK, Engman ML, Sund F, et al. Cytomegalovirus-specific CD4 and CD8 T cell responses in infants and children. Scand J Immunol 2013;77(2):135-143

15 Demirel G, Celik IH, Canpolat FE, Dilmen U. Cytomegalovirus infection in preterm triplets transmitted via breast milk. J Trop Pediatr 2014;60(2):168-170

16 Stronati M, Lombardi G, Di Comite A, Fanos V. Breastfeeding and cytomegalovirus infections. J Chemother 2007;19(Suppl 2):49-51

17 Embil JA, Ozere RL, Haldane EV. Congenital cytomegalovirus infection in two siblings from consecutive pregnancies. J Pediatr 1970;77(3):417-421

18 Gessler P, Bischoff GA, Wiegand D, Essers B, Bossart W. Cytomegalovirus-associated necrotizing enterocolitis in a preterm twin after breastfeeding. J Perinatol 2004;24(2): 124-126

19 Mosca F, Pugni L. Cytomegalovirus infection: the state of the art. J Chemother 2007;19(Suppl 2):46-48

20 Nigro G, La Torre R, Anceschi MM, Mazzocco M, Cosmi EV. Hyperimmunoglobulin therapy for a twin fetus with cytomegalovirus infection and growth restriction. Am J Obstet Gynecol 1999; 180(5):1222-1226

21 Picone O, Costa J-M, Dejean A, Ville Y. Is fetal gender a risk factor for severe congenital cytomegalovirus infection? Prenat Diagn 2005; 25(1):34-38

22 Yinon Y, Yagel S, Tepperberg-Dikawa M, Feldman B, Schiff E, Lipitz S. Prenatal diagnosis and outcome of con genital cytomegalovirus infection in twin pregnancies. BJOG 2006;113 (Suppl 3):295-300 